\title{
Association between soil-transmitted helminthiasis and hemoglobin concentration in primary school children
}

\author{
Rita Angraini, MD; Y Dimyati, MD; Bidasari Lubis, MD; Syahril Pasaribu, MD; \\ Chairuddin P Lubis, MD
}

\begin{abstract}
Objectives To determine the association between intestinal helminthiasis and hemoglobin $(\mathrm{Hb})$ concentration and to observe the effect of single dose albendazole treatment on $\mathrm{Hb}$ concentration. Methods An experimental study was carried out from March to July 2002 on primary school children at Suka Village, Tiga Panah Subdistrict, Karo Regency, North Sumatera Province. From 366 children who suffered from helminthiasis, 113 were selected as subjects by simple random sampling. Subjects were treated with a single oral dose of $400 \mathrm{mg}$ albendazole. $\mathrm{Hb}$ concentration was examined using the cyanide method twice i.e., prior to and three months after treatment with albendazole.

Results It was found that among 113 subjects, the prevalences of Ascaris lumbricoides, Trichuris trichiura, and mixed infestation were $18.3 \%, 40.4 \%$, and $41.3 \%$, respectively, while the prevalence of anemia was $33.0 \%$. There was no significant difference in age, gender, nutritional status, and mean $\mathrm{Hb}$ concentration between children suffering from the different types of worm infestation $(P>0.05)$. For each type of infestation, there were significant differences in mean $\mathrm{Hb}$ concentration and anemia prevalence before and after treatment $(P<0.05)$.

Conclusions There was no difference between the $\mathrm{Hb}$ concentrations of children suffering from Ascaris lumbricoides, Trichuris trichiura, and mixed-type worm infestations. Single dose $400 \mathrm{mg}$ albendazole was beneficial in increasing $\mathrm{Hb}$ concentration and reducing the occurrence of anemia [Paediatr Indones 2005; 45:24-30].
\end{abstract}

Keywords: helminthiasis, $\mathrm{Hb}$ concentration, albendazole treatment, anemia
I ntestinal parasitic infection caused by nematodes is one of the main public health problems in developing countries, including Indonesia. ${ }^{1}$ Epidemics of these diseases occur more frequently in tropical and subtropical areas. In some cases the disease may also be found in moderate and cold climate areas. ${ }^{2}$ Soil-transmitted helminths (STH) are those which are infectious during their growth inside susceptible soil. The primary worm species in relation to humans are Ascaris lumbricoides, Trichuris trichiura, and hookworm, ${ }^{3}$ which have already infected more than a quarter of the world's population. ${ }^{4}$ WHO reported that more than 2 billion people have been infected by STH, of which more than 1 billion by Ascaris lumbricoides, 5,6 750 million by Trichuris trichiura, and 900 million by hookworm. 2,7,8 Ascaris lumbricoides mainly affects children under 10 years of age with the highest prevalence in the 7 to 12 year age group. ${ }^{9}$ Trichuriasis

From the Department of Child Health, Medical School, University of North Sumatera/Adam Malik Hospital, Medan.

Reprint requests to: Rita Angraini, MD, Department of Child Health, University of Sumatera Utara, Adam Malik Hospital, Jl. Bunga Lau No.17 Medan 20136, Tel/Fax: 061-8361721

Presented at the International Seminar on Parasitology and the $9^{\text {th }}$ Congress of the Indonesian Parasitic Disease Control Association; 2002 Sept 11-12; Bogor, Indonesia. 
has the highest prevalence between the ages of 5 and 15 years, ${ }^{2}$ while hookworm infection is most prevalent in children 12 to 17 years old. ${ }^{9}$

The major manifestations of worm infestation are anemia and hypoalbuminemia., 2,8,10-12 Iron deficiency anemia may occur depending on several factors, such as iron intake, iron storage, and the duration of infection. ${ }^{10,13}$ One of the efforts to overcome anemia in children due to worm infestation is the implementation of a worm infection control program. ${ }^{14}$ This study was conducted to compare hemoglobin $(\mathrm{Hb})$ concentrations of children suffering from either Ascaris lumbricoides, Trichuris trichiura, or mixed infection and to evaluate the efficacy of a single dose of $400 \mathrm{mg}$ albendazole in increasing $\mathrm{Hb}$ concentration.

\section{Methods}

This study was a randomized clinical trial carried out from March to July 2002 in primary schoolchildren in Suka Village, Tiga Panah Subdistrict, Karo Regency, North Sumatera Province. Stool was collected in a plastic bottle and examined using the quantitative Kato-Katz method. ${ }^{15}$ Stool examination was done in the Pediatrics Laboratory, Medical School, University of Sumatera Utara, Adam Malik Hospital, Medan. Of the children who were positive for worm infection, 113 were selected as study subjects by simple random sampling.

\section{Eligibility criteria}

Primary schoolchildren of any level who agreed to participate in the study, had written parental permission, positive stool examination for worm eggs, good nutritional status, had not taken anthelmintic drugs for at least one month before the study, did not have any contraindication for anthelmintic agents, and were living in the vicinity of the study location, were included in this study. They were excluded if they were absent from school or withdrew from the school, or suffered from any serious infection.

\section{Study protocol}

Subjects were simultaneously given a single dose of oral $400 \mathrm{mg}$ albendazole, witnessed by the investigators. Prior to treatment, the nutritional status of each subject was determined based on the standard recommended by the Center for Disease Control and Prevention, National Center for Health Statistics (CDC, NCHS). ${ }^{16}$

Examination of $\mathrm{Hb}$ concentration using the cyanide method ${ }^{17}$ was carried out twice; prior to and three months after treatment, to monitor $\mathrm{Hb}$ concentration improvement and anemia prevalence. The examination was conducted at the Emergency Installation of Adam Malik Hospital, Medan. Hb concentration was corrected for high altitude according to Dirren et al, as the study area was located $1400 \mathrm{~m}$ above sea level. A child was considered anemic if his/ her $\mathrm{Hb}$ concentration was less than $11.6 \mathrm{~g} / \mathrm{dl} .{ }^{18}$

\section{Data analysis}

Analysis of variance (ANOVA) was performed to determine any difference in $\mathrm{Hb}$ concentration between children suffering from the different types of worm infection. Paired t-test to evaluate the difference in $\mathrm{Hb}$ concentrations before and after treatment and chi-square test to evaluate the association between anemia and albendazole treatment, age, sex, and nutritional status, respectively, were done. A $P$ value of $<0.05$ was considered significant. Data were analyzed using SPSS 10.0 for Windows.

\section{Results}

Out of 434 children who participated in the study, 336 children $(84.6 \%)$ were positive for intestinal helminthiasis. Among 113 selected subjects, 4 children were excluded due to lack of written parental permission ( 2 children) and absence from school during the study (2 children). Out of the 109 children who completed the study, 20 (18.3\%) suffered from Ascaris lumbricoides, 44 (40.4\%) from Trichuris trichiura, and 45 (41.3\%) from mixed-type worm infections.

There was no difference in children's age group, sex, and nutritional status among the different types of worm infection (Table 1). There was no difference in average $\mathrm{Hb}$ concentration between children suffering from the different types of worm infection (Table 2). There was a significant difference in the mean $\mathrm{Hb}$ concentration before and after treatment for each type of worm infection $(\mathrm{P}<0.05)$ (Table 3). 
Table 1. Subject characteristics

\begin{tabular}{lccccc}
\hline \multicolumn{7}{c}{ Type of infection } \\
\hline Characteristics & A. Iumbricoides & T. trichiura & Mixed infection & Total \\
\hline \multicolumn{1}{l}{ Age (years) } & $\mathbf{n}$ & $\mathbf{n}$ & $\mathbf{n}$ & $\mathbf{n}$ & $\%$ \\
$\mathbf{6 - 7}$ & & & & & \\
$\mathbf{8 - 9}$ & 4 & 10 & 8 & 22 & 20.2 \\
$\mathbf{1 0 - 1 1}$ & 5 & 16 & 17 & 38 & 34.9 \\
$\mathbf{1 2 - 3}$ & 7 & 13 & 19 & 39 & 35.8 \\
Sex & 4 & 5 & 1 & 10 & 9.2 \\
Male & & & & & \\
Female & 12 & 21 & 22 & 55 & 50.5 \\
Nutritional status & 8 & 23 & 23 & 54 & 49.5 \\
Normal & & & & & \\
Mild malnutrition & 9 & 19 & 19 & 47 & 43.1 \\
Moderate malnutrition & 5 & 7 & 22 & 45 & 41.3 \\
& 6 & & 4 & 17 & 15.6 \\
\hline
\end{tabular}

Table 2. Hb concentrations in the different types of Worm INFECTION

\begin{tabular}{lllll}
\hline Type of worm & \multicolumn{4}{c}{ Hb concentration $(\mathbf{m g} / \mathbf{d l})$} \\
\hline & $\mathbf{n}$ & Mean & SD & P \\
\hline A. Iumbricoides & 20 & 12.60 & 2.36 & 0.620 \\
T. trichiura & 44 & 13.20 & 2.22 & \\
Mixed infection & 45 & 13.10 & 2.42 & \\
\hline
\end{tabular}

Table 3. Hb concentration before and after treatment in EACH TYPE OF WORM INFECTION

\begin{tabular}{lccll}
\hline Type of worm & \multicolumn{4}{c}{ Hb concentration $(\mathbf{m g} / \mathbf{d l})$} \\
\hline & $\mathbf{N}$ & Mean & SD & $\mathbf{P}$ \\
\hline Ascaris lumbricoides & & & & \\
$\quad$ Before treatment & 20 & 12.60 & 2.36 & $0.006^{*}$ \\
$\quad$ After treatment & 20 & 14.45 & 1.1367 & \\
Trichiuris trichiura & & & & \\
$\quad$ Before treatment & 44 & 13.20 & 2.22 & $0.014^{*}$ \\
$\quad$ After treatment & 44 & 14.2159 & 2.2986 & \\
Mixed infections & & & & \\
$\quad$ Before treatment & 45 & 13.10 & 2.42 & $0.000^{*}$ \\
$\quad$ After treatment & 45 & 14.5556 & 1.8066 & \\
\hline
\end{tabular}

Table 4. Change in anemia prevalence before and after treatment IN EACH TYPE OF WORM INFECTION

\begin{tabular}{llllll}
\hline Type of worm & $\mathbf{( + )}$ Anemia & \multicolumn{2}{l}{$(\mathbf{-})$ Anemia } & $\mathbf{P}$ \\
\hline & $\mathbf{n}$ & $\%$ & $\mathbf{n}$ & $\%$ & \\
\hline $\begin{array}{l}\text { A. Iumbricoides } \\
\quad \text { Before }\end{array}$ & 8 & 40.0 & 12 & 60.0 & $0.002^{*}$ \\
$\quad$ After & 0 & 0 & 20 & 100.0 & \\
$\begin{array}{l}\text { T. trichiura } \\
\quad \text { Before }\end{array}$ & 15 & 34.1 & 29 & 659 & $0.049^{*}$ \\
$\quad$ After & 7 & 15.9 & 37 & 84.1 & \\
$\begin{array}{l}\text { Mixed infection } \\
\quad \text { Before }\end{array}$ & 13 & 28.9 & 32 & 71.1 & $0.006^{*}$ \\
$\quad$ After & 3 & 6.7 & 42 & 93.3 & \\
\hline
\end{tabular}


The proportions of anemia before and after treatment were significantly different for each type of worm infection $(P<0.05)$ (Table 4, Figures 1, 2, and 3).

\section{Discussion}

From 109 subjects with worm infection, the prevalence of Ascaris lumbricoides, Trichuris trichiura, and mixedtype worm infection were $18.3 \%, 40.4 \%$, and $41.3 \%$, respectively. The relatively high prevalence of mixedtype worm infection in this study is comparable to that in a previous study on primary school children in North Sumatera, in which the prevalence was found to be $79.7 \% .{ }^{19}$ In South India, Nallam et al (1998) also found similar results. ${ }^{20}$ Smith et al (2001) discovered the prevalence of Ascaris lumbricoides and Trichuris trichiura to be $45 \%$ and $38 \%$, respectively. Approximately a quarter of these subjects (25.8\%) had concomitant infestation of Ascaris lumbricoides and

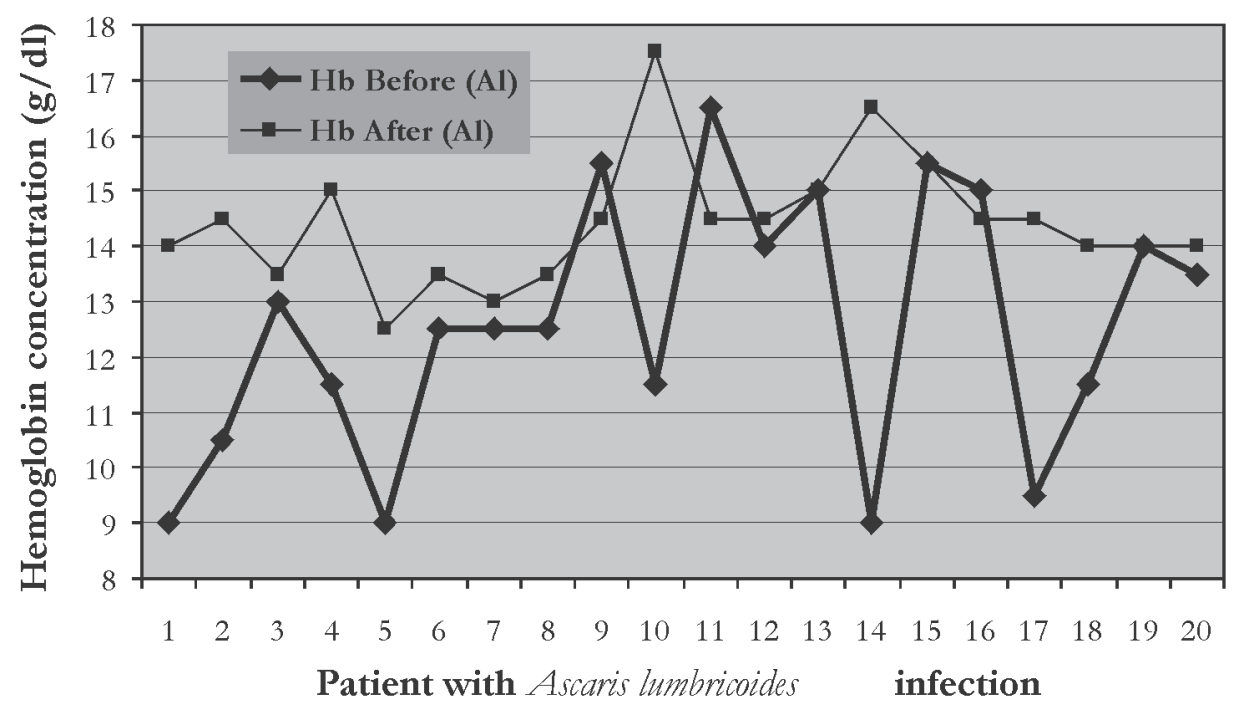

Figure 1. Hemoglobin concentration before and after treatment of Ascaris LUMBRICOIDES INFECTION

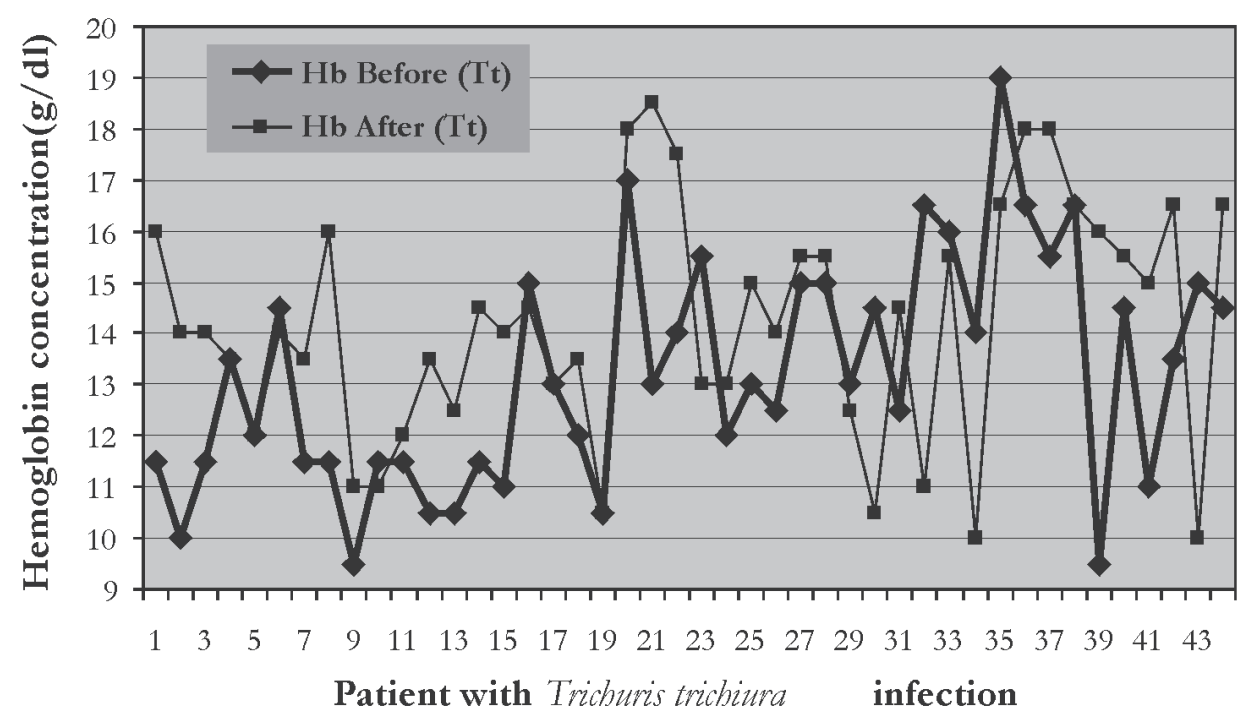

Figure 2. Hemoglobin CONCENTRATION BEFORE AND AFTER TREATMENT OF TRICHURIS TRICHIURA INFECTION 


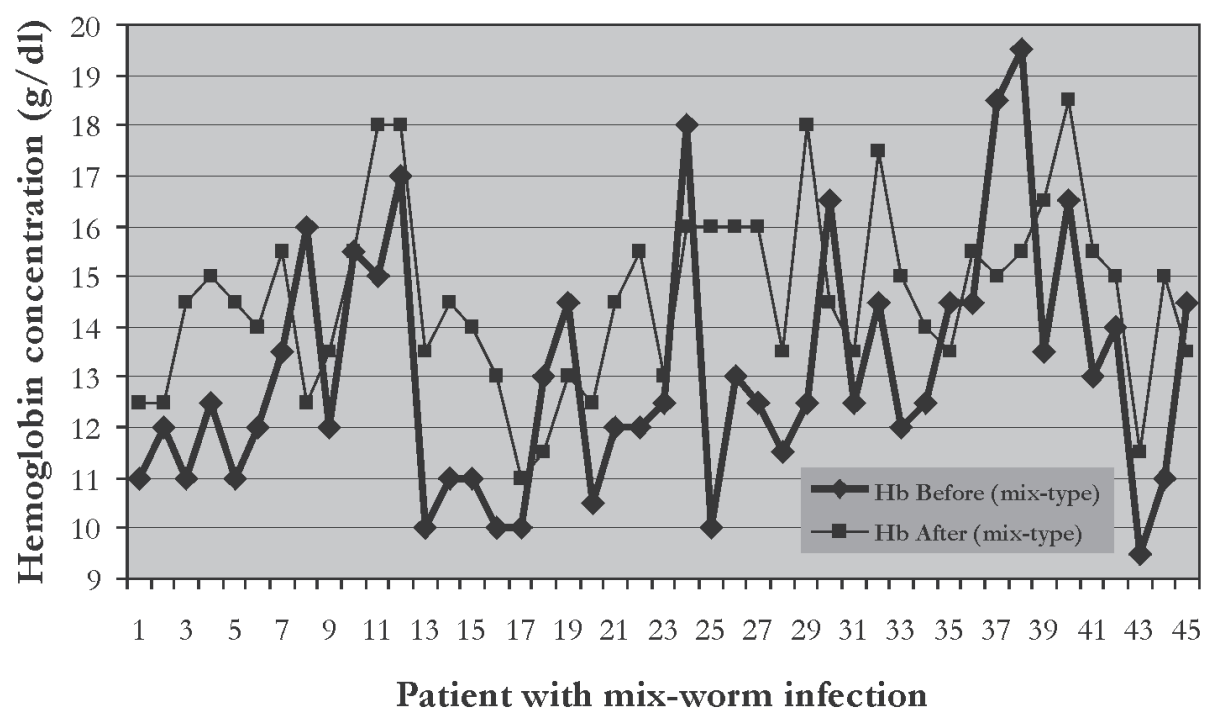

Figure 3. Hemoglobin concentration before and AFter treatment of miXed-Type WORM INFECTION

Trichuris trichiura. ${ }^{21}$ These findings show that there was a positive interaction between Ascaris lumbricoides and Trichuris trichiura infestation. A high intensity of infestation with Ascaris lumbricoides has been significantly associated with that of Trichuris trichiura. It has been suggested that the high prevalence of concomitant infection is because both worm species share the same fecal-oral route of infection. ${ }^{21,22}$

The high prevalence of intestinal helminthiasis in primary school children was probably due to a poor hygienic standard and high outdoor activity, which renders them susceptible to worm transmission. ${ }^{9}$

Data showed no significant difference in the children's age group, sex, and nutritional status between the three types of worm infections. The same finding has been described by Pasaribu et al in 1996. ${ }^{19}$ Meanwhile, Norhayati et al (1997), ${ }^{22}$ Ozumba et al (2002), ${ }^{9}$ and Smith et al (2001) ${ }^{21}$ found a significant difference in Ascaris lumbricoides and Trichuris trichiura prevalence among different age groups but no difference between sexes. In Madagascar, there was a higher prevalence of Ascaris lumbricoides in boys than in girls. This shows that sex may or may not have a role in the risk of worm infection depending on regional, environmental, and behavioral factors. ${ }^{20}$

In this study, no difference was found in the children's $\mathrm{Hb}$ concentration between each type of worm infection in (Table 2). Greenberg et al discovered that Trichuris trichiura infection had a positive correlation with a low $\mathrm{Hb}$ concentration but not with iron deficiency. ${ }^{23}$ Nallam et al (1998) found that Ascaris lumbricoides infection had no role in causing anemia, ${ }^{20}$ while Blumenthal et al (1976) in Louisiana reported that ascariasis influenced nutritional status and found that almost $50 \%$ of subjects suffered from anemia and $40 \%$ had inadequate transferrin saturation. ${ }^{24}$ Robertson et al (1992) found that children with severe trichuriasis or mixed infection of Trichuris trichiura and hookworm had low $\mathrm{Hb}$ concentration. ${ }^{25}$ Stoltzfus et al reported that Ascaris lumbricoides infection is related to anemia but not to intestinal blood loss. ${ }^{26}$

Our study showed the benefits of administering a single oral dose of $400 \mathrm{mg}$ albendazole in improving $\mathrm{Hb}$ concentration and decreasing the prevalence of anemia. This was evident in the statistically significant differences in $\mathrm{Hb}$ concentration and anemia prevalence before and after treatment $(\mathrm{P}<0.005)$ (Tables 3 and 4, Figures 1, 2 , and 3). The result was similar to that of Robertson's study. ${ }^{25}$ Oguntibeju described that worm infection had a relation with changes in hematological indices. 27

In this study, due to limitations, no further hematological examination was performed to determine other possible causes of anemia. Therefore, we assumed that intestinal helminthiasis is the only cause of anemia in our subjects, although other factors could not be disregarded. We suggest that further studies be carried out with more detail and more comprehensive evaluation for other causes of anemia. 
Rita Angraini et al: Association between soil-transmitted helminthiasis and hemoglobin concentration

In conclusion, there is no difference in the hemoglobin concentration of children suffering from either Ascaris lumbricoides, Trichuris trichiura, or mixed-type worm infection. A single oral dose of $400 \mathrm{mg}$ albendazole is beneficial in improving hemoglobin concentration and reducing the prevalence of anemia.

\section{References}

1. Pasaribu S. Penentuan frekuensi optimal pengobatan massal askariasis dengan albendazole pada anak usia sekolah dasar [dissertation]. Medan: University of Sumatera Utara; 2004.

2. Mahmoud AAF. Intestinal nematodes. In: Mandell GL, Bennett JE, Dolin R, editors. Mandell, Douglas, and Bennett's principles and practice of infectious disease. 5th ed. New York: Churchill Livingstone; 2000. p. 2938-9.

3. Margono SS. Nematoda usus. In: Gandahusada S, Ilahude HD, Pribadi W, editors. Parasitologi kedokteran. 3rd ed. Jakarta: Fakultas Kedokteran Universitas Indonesia; 1998. p. 8-34.

4. Strickland GT. General principles. In: Hunters' tropical medicine. 8th ed. Philadelphia: WB Saunders Company; 2000. p. 722-4.

5. Bundy DAP, DeSilva N. Intestinal nematodes that migrate through lungs (ascariasis). In: Strickland GT, editor. Hunters' tropical medicine. Philadelphia: WB Saunders Company; 2000. p. 726-30.

6. Kazura JW. Ascariasis. In: Behrman RE, Kliegman RM, Arvin AM, editors. Nelson textbook of pediatrics. 15th ed. Philadelphia: WB Saunders Company; 1996. p. 992-3

7. Bundy DAP, Cooper E. Nematodes limited to the intestinal tract (Enterobius vermicularis, Trichuris trichiura, and Capillaria phillippinensis). In: Strickland GT, editor. Hunters' tropical medicine. 8th ed. Philadelphia: WB Saunders Company; 2000. p. 719-24.

8. Warren KS, Bundy DAP, Anderson RM, et al. Helminth infection. In: Jamison DT, Mosley WH, Measham AR, Bobadilla JL, editors. Disease control priorities in developing countries. New York: Oxford University Press; 1993. p. 131-60.

9. Ozumba UC, Ozumba N. Patterns of helminth infection in the human at the university of Nigeria teaching hospital, Enugu, Nigeria. J Health Sci 2002;48:263-8.

10. Gilman RH. Intestinal nematodes that migrate through skin and lung. In: Strickland GT, editor. Hunters' tropi- cal medicine. 8th ed. Philadelphia: WB Saunders Company; 2000. p. 730-5.

11. King CH. Hookworms. In: Behrman RE, Kliegman RM, Arvin AM, editors. Nelson textbook of pediatrics. 15th ed. Philadelphia: WB Saunders Company; 1996. p. 1000-1.

12. Committee on infectious diseases. Hookworm infections. In: Pickering LK, Peter G, Baker CJ, Gerber MA, MacDonald NE, editors. 2000 red book: report of the committee on infectious diseases. 25th ed. Elk Grove Village: American Academy of Pediatrics; 2000. p. 321.

13. Stlotzfus RJ, Dreyfuss ML, Chwaya HM, Albanico M. Hookworm control as a strategy to prevent iron deficiency. Nutrition Reviews 1997;55:223-32.

14. Stlotzfus RJ, Chwaya HM, Tielsch JM, Schulze KJ, Albanico, Savioli L. Epidemiology of iron deficiency anemia in Zanzibar schoolchildren: the importance of hookworms. Am J Clin Nutr 1997;65:153-9.

15. Sembiring TUJ. Protozoologi dan penuntun praktikum parasitologi. Medan: Pendidikan Analis Kesehatan Depkes RI; 1997. p. 131-5.

16. Kuczmarski RJ, Ogden CL, Grumer-Strawn LG. CDC growth charts: United States. Advanced data-NCHS 2000;314:1-28.

17. Bain BJ, Bates I. Basic haematological techniques. In: Lewis SM, Bain BJ, Bates I, editors. Dacie and Lewis practical hematology. 9th ed. London: Churchill Livingstone; 2001. p. 19-33.

18. Dirren H, Logman MH, Barclay DV, Freire WB. Altitude correction for hemoglobin. Eur J Clin Nutr 1994;48:625-32.

19. Pasaribu S, Lubis CP. Diagnostic of hookworm infection by using modified Kato-Katz thick smear. Proceedings of the Congress of Infectious Diseases; 1996; Kuala Lumpur, Malaysia.

20. Nallam NR, Paul I \& Gnanamani G. Anemia and hypoalbuminemia as an adjunct to soil-transmitted helminthiasis among slum school children in Visakhapatnam. South India, Asia Pacific J Clin Nutr 1998;7:164-9.

21. Smith HM, De Kaminsky RG, Niwas S, Soto RJ, Jolly PE. Prevalence and intensity of infections of Acaris lumbricoides and Trichuris trichiura and associated sociodemographic variables in four rural Honduran communities. Mem Inst Oswaldo Cruz, Rio de Janeiro 2001;96:303-14.

22. Norhayati M, Zainudin B, Mohammod CG, Oothuman P, Azizi O, Fatmah MS. The prevalence of Trichuris, 


\section{Paediatrica Indonesiana}

Ascaris and hookworm infection in Orang Asli children. Southeast Asian J Trop Med Public Health 1997;28:161-8.

23. Greenberg ER, Cline BL. Is trichuriasis associated with iron deficiency anemia? Am J Trop Med Hyg 1979;28:770-2.

24. Blumenthal DS \& Schultz MG. Effects of Ascaris infection on nutritional status in children. Am J Trop Med Hyg 1976;25:682-90.

25. Robertson LJ, Crompton DWT \& Nesheim MC. Hemoglobin concentration and concomitant infections of hookworm and Trichuris trichiura in Panamanian primary school children. Transactions of the Royal Society of Tropical Medicine and Hygiene 1992; 86:654-6.

26. Stoltzfus RJ, Albonico, Chwaya M, Savioli L, Tielsch J, Schulze K, et al. Hemoquant determination of hookworm-related blood loss and its in iron deficiency in African children. Am J Trop Med Hyg 1996;55:399-404.

27. Oguntibeju OO. Parasitic infection and anemia: the prevalence in a rural hospital setting. JIACM 2003;210-2. 